\title{
Phytochemical Investigation of Schleichera oleosa (Lour.) Oken Leaf
}

\author{
Noushin Anjum ${ }^{1}$, Md. Jamal Hossain ${ }^{1}$, Mohammad Rashedul Haque ${ }^{1}$, Akhtaruzzaman \\ Chowdhury $^{2}$, Mohammad A. Rashid ${ }^{1}$ and Md. Ruhul Kuddus ${ }^{1}$ \\ ${ }^{1}$ Phytochemical Research Laboratory, Department of Pharmaceutical Chemistry, Faculty of Pharmacy \\ University of Dhaka, Dhaka-1000, Bangladesh \\ ${ }^{2}$ Department of Chemistry, Government Bangla College, Mirpur, Dhaka-1216, Bangladesh
}

(Received: October 12, 2020; Accepted: December 28, 2020; Published (web): January 28, 2021)

\begin{abstract}
Schleichera oleosa (Lour.) Oken. is a medicinal plant of Bangladesh with enormous traditional applications in folk medicine. The current study was designed to isolate the secondary metabolites by successive chromatographic separation of $n$-hexane and dichloromethane soluble fractions of a methanol extract of leaves of S. oleosa. A total of four compounds were separated and identified as 5,7-dihydroxy4'-methoxyflavone, stigmasterol, lupeol and betulinic acid. The structures of the isolated compounds were elucidated by analysis of their ${ }^{1} \mathrm{H}$ NMR data and comparison with published values.
\end{abstract}

Key words: Schleichera oleosa, phytochemical, chromatography, NMR.

\section{Introduction}

Bangladesh is an excellent reservoir of medicinal plants which is the vital source of medicine for mankind (Rashid et al., 2015). More than 500 different species of medicinal plants grow in Bangladesh. A major part of these species is used in folk medicines for the cure of various ailments (Uddin et al., 2015). Medicinal values of these plants are attributed to the bioactive molecules which can exert substantial biological effects on the human body. These natural compounds formed the basis for the development of modern pharmaceutical drugs. Moreover, plant-derived natural products have attracted the attention of scientists due to their minimal side effects. Therefore, the research interest in the phytochemical studies of medicinal plants is rising in order to discover the bioactive leads (Cragg and Newman, 2013; Veeresham, 2012 and McChesney et al., 2007).

Schleichera oleosa (Lour.) Oken (Family: Sapindaceae) is a deciduous, evergreen, medium sized tree which is widely distributed in the Indian subcontinent and Southeast Asia. The plant is locally familiar as Kushum (Thind et al., 2011). Traditionally it is used as folk medicine for several ailments such as pain, infection and dysentery (Pokhrel et al., 2015). Kusum oil, a seed oil of $S$. oleosa, is used for the treatment of rheumatism, skin diseases and also for promoting hair growth (Palanuvej and Vipunngeun et al., 2008). Bark extract was reported to cure gynecological disorder, inflamed skin and ulcers (Mohapatra and Sahoo, 2008). Previous phytochemical study led to isolation of phenolic compounds, fatty acids, tannins, hydroxyl sterols and triterpenoids from this plant (Goswami and Singh, 2017). Bioactive triterpenoids isolated from $S$. oleosa bark exhibited antimicrobial potentials against bacterial and fungal pathogens (Ghosh et al., 2011). Hydroxylated sterols isolated from the bark of S. oleosa showed potent anticancer properties (Pettit et al., 2000). As part of our continuous study on medicinal plants of Bangladesh (Fahad et al., 2020;

Corresponding author: Md. Ruhul Kuddus; Email: ruhulkuddus@du.ac.bd

DOI: https://doi.org/10.3329/bpj.v24i1.51633 
Islam et al., 2019; Moniruzzaman et al., 2019) we studied the chemical constituents of S. oleosa and we, herein, report the results of our phytochemical investigation of this plant species.

\section{Materials and Methods}

Collection and preparation of plant material: The leaves of $S$. oleosa were collected from Botanical Garden, Mirpur, Dhaka-1216, Bangladesh and was authenticated (Accession no. DACB 63763) in Bangladesh National Herbarium, Mirpur, Dhaka1216, Bangladesh. After collection, the plant samples were washed and dried at room temperature. The dried leaves were grinded to a coarse powder. The powdered sample $(500 \mathrm{~g})$ of $S$. oleosa was soaked in methanol for few days. The filtrate was concentrated to dryness with a rotary evaporator. About $5 \mathrm{~g}$ of the dried methanolic extract of $S$. oleosa was subjected for Kupchan partitioning (Van-Wagenen et al., 1993) to yield $n$-hexane, dichloromethane and ethyl acetate soluble fractions.

Isolation of chemical compounds: An aliquot of the dichloromethane soluble materials $(300 \mathrm{mg})$ was subjected to gel permeation chromatography over Sephadex (LH-20) from which fifty nine subfractions was collected, each $20.0 \mathrm{ml}$. Preparative TLC screening of sub-fractions 49-53 over silica gel using toluene: ethyl acetate (80:20) provided compound 1. On the other hand, the dichloromethane soluble fraction $(500 \mathrm{mg}$ ) was fractionated by column chromatography (CC) over silica gel (Kieselgel 60, mesh 70-230) using a mixture of $n$-hexane and ethyl acetate in order of increasing polarities. Preparative TLC of column fractions 56-59 and 45-51 over silica gel using toluene in ethyl acetate (98:2) as the developing solvent afforded compound $\mathbf{2}$ and compound $\mathbf{3}$, respectively.

\section{Properties of isolated compounds}

5,7-dihydroxy-4'-methoxyflavone (1): $(0.5 \mathrm{mg}$, $0.01 \%$ yield); ${ }^{1} \mathrm{H}$ NMR (400 MHz, $\mathrm{CDCl}_{3}$ ): $\delta 7.85$ $\left(2 \mathrm{H}, \mathrm{d}, J=8.0 \mathrm{~Hz}, \mathrm{H}-2^{\prime} / \mathrm{H}-6^{\prime}\right), 7.03(1 \mathrm{H}, \mathrm{d}, J=8.0$ $\left.\mathrm{Hz}, \mathrm{H}-3^{\prime} / \mathrm{H}-5^{\prime}\right), 6.60(1 \mathrm{H}, \mathrm{s}, \mathrm{H}-3), 6.46(1 \mathrm{H}, \mathrm{d}, J=2.0$
Hz, H-6/H-8), 6.30 (1H, d, J = 2.0 Hz, H-6/H-8), 3.90 $\left(3 \mathrm{H}, \mathrm{s},-\mathrm{OCH}_{3}, \mathrm{C}-4^{\prime}\right)$.

Stigmasterol (2): (2.9 mg, $0.058 \%$ yield); ${ }^{1} \mathrm{H}$ NMR (400 MHz, $\mathrm{CDCl}_{3}$ ) spectral data was identical to published values (Pierre and Moses, 2015).

Lupeol (3a): ${ }^{1} \mathrm{H}$ NMR (400 MHz, $\mathrm{CDCl}_{3}$ ): $\delta 4.71$ $\left(1 \mathrm{H}\right.$, br. s, $\left.\mathrm{H}_{\mathrm{a}}-29\right), 4.59\left(1 \mathrm{H}\right.$, br. s, $\left.\mathrm{H}_{\mathrm{b}}-29\right), 3.20(1 \mathrm{H}$, m, H-3), 1.69 (3H, s, $\left.\mathrm{H}_{3}-30\right), 1.02\left(3 \mathrm{H}, \mathrm{s}, \mathrm{H}_{3}-25\right)$, 0.96 (3H, s, $\left.\mathrm{H}_{3}-23\right), 0.93$ (3H, s, $\left.\mathrm{H}_{3}-26\right), 0.82$ (3H, s, $\left.\mathrm{H}_{3}-28\right), 0.78$ (3H, s, $\left.\mathrm{H}_{3}-24\right)$.

Betulinic acid (3b): ${ }^{1} \mathrm{H}$ NMR $(400 \mathrm{MHz}$, $\left.\mathrm{CDCl}_{3}\right): \delta 4.71\left(1 \mathrm{H}\right.$, br. s, $\left.\mathrm{H}_{\mathrm{b}}-29\right), 4.59\left(1 \mathrm{H}\right.$, br. s, $\mathrm{H}_{\mathrm{a}^{-}}$ 29), 3.25 (1H, m, H-3), 3.02 (1H, m, H-19), 1.70 (3H, s, H-30), 0.99, 0.92, 0.89, 0.78, $0.76(5 \mathrm{~s}$, each $3 \mathrm{H}$, all tertiary $-\mathrm{CH}_{3}$ ).

\section{Results and Discussion}

Successive chromatographic separation and purification of $n$-hexane and dichloromethane soluble materials of $S$. oleosa leaf extract yielded a total of four compounds (Figure 1). The structures of these compounds were established as 5,7-dihydroxy-4'methoxyflavone (1), stigmasterol (2), lupeol (3a) and betulinic acid (3b) by analyses of their ${ }^{1} \mathrm{H}$ NMR spectroscopic data as well as by comparison with published reports.

The ${ }^{1} \mathrm{H}$ NMR spectrum $\left(400 \mathrm{MHz}, \mathrm{CDCl}_{3}\right.$ ) of compound 1 displayed a pair of ortho-coupled $(J=$ $8.0 \mathrm{~Hz}$ ) doublets at $\delta 7.03$ and 7.85 which indicated that the " $\mathrm{B}$ " is substituted at $\mathrm{C}-4$ ' and thus these were assigned to $\mathrm{H}-3^{\prime}$ \& $\mathrm{H}-5^{\prime}$ and $\mathrm{H}-2^{\prime}$ \& $\mathrm{H}-6^{\prime}$, respectively. The singlet at $\delta 3.90$ which obviously indicated that, a methoxy group was present in the structure at C-4' position. The spectrum also showed two meta-coupled doublets $(J=2.0 \mathrm{~Hz})$ at $\delta 6.30$ and 6.46 which were assigned to $\mathrm{H}-6$ and $\mathrm{H}-8$ or vice versa. The lone singlet of one proton intensity at 6.60 could be ascribed to $\mathrm{H}-3$. All these ${ }^{1} \mathrm{H}$ NMR data of compound $\mathbf{1}$ are in close agreement with the published value of 5,7-dihydroxy-4'-methoxyflavone or acacetin (Gomes et al., 2011). Therefore, compound 1 was characterized as 5,7-dihydroxy-4'methoxyflavone (Figure 1). 
The ${ }^{1} \mathrm{H}$ NMR spectral features of compound 2 were in close agreement with the ${ }^{1} \mathrm{H}$ NMR spectrum recorded for stigmasterol previously isolated in our laboratory (Sufian et al., 2015; Chowdhury et al., 2013). Therefore, compound 2 was identified as stigmasterol (Figure 1).

The ${ }^{1} \mathrm{H}$ NMR spectrum (400 $\mathrm{MHz}, \mathrm{CDCl}_{3}$ ) of compound $\mathbf{3}$ displayed signals assignable to a mixture of two closely related triterpenoids i.e- lupeol (3a) and betulinic acid (3b). The ${ }^{1} \mathrm{H}$ NMR spectral signal assignable to compound 3a revealed a multiplet at $\delta$ 3.20 , suggesting the presence of an oxymethine proton, $\mathrm{H}-3$ in the triterpene nucleus. The ${ }^{1} \mathrm{H}$ NMR spectrum displayed five three proton singlets at $\delta$ $0.78,0.82,0.93,0.96$ and 1.02 which were assigned to the methyl groups at C-24, C-28, C-26, C-23 and $\mathrm{C}-25$, respectively. The spectrum also revealed two broad singlets at $\delta 4.71\left(1 \mathrm{H}\right.$, br. $\left.\mathrm{s}, \mathrm{H}_{\mathrm{a}}-29\right)$ and 4.59 $\left(1 \mathrm{H}\right.$, br. $\left.\mathrm{s}, \mathrm{H}_{\mathrm{b}}-29\right)$, together with an allylic methyl proton signal at $\delta 1.69\left(3 \mathrm{H}, \mathrm{s}, \mathrm{H}_{3}-30\right)$ confirmed an isopropenyl functionality. Therefore, compound 3a was characterized as lupeol (Figure 1). This was further confirmed by comparing its ${ }^{1} \mathrm{H}$ NMR data with the published values (Fahad et al., 2020; Sufian et al., 2015).

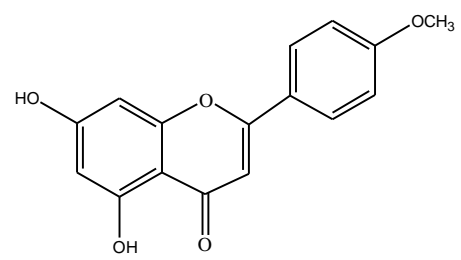

5,7-dihydroxy-4'-methoxyflavone (1)

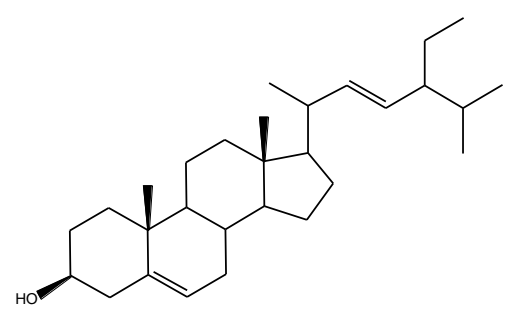

Stigmasterol (2)

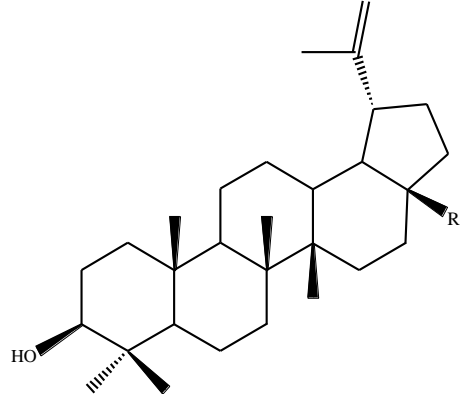

$\mathrm{R}=-\mathrm{CH}_{3}$, Lupeol (3a)

$\mathrm{R}=-\mathrm{COOH}$, Betulinic acid (3b)

Figure 1. Compounds isolated from Schleichera oleosa.

The ${ }^{1} \mathrm{H}$ NMR spectral data assignable to compound 3b showed five methyl singlets at $\delta 0.76$, $0.78,0.89,0.92,0.99$, a vinylic methyl group at $\delta$ $1.70(3 \mathrm{H}, \mathrm{s})$ and a pair of exomethylene protons at $\delta$ $4.59(1 \mathrm{H}$, br. s) and $\delta 4.71(1 \mathrm{H}$, br. s). The spectrum also displayed a multiplet at $\delta 3.25$ which could be ascribed to the oxygenated proton of C-3 (H-3). On the basis of the spectral data, compound $\mathbf{3 b}$ was characterized as betulinic acid (Figure 1) which was further confirmed by comparing its ${ }^{1} \mathrm{H}$ NMR data with the published report (Haque et al., 2013).

\section{Conclusion}

Phytochemical investigation of the $n$-hexane and dichloromethane soluble fractions of $S$. oleosa leaf extract yielded a total of four compounds which were characterized as 5,7-dihydroxy-4'-methoxyflavone
(1), stigmasterol (2), lupeol (3a) and betulinic acid (3b) on the basis of their spectral data. Further studies are necessary to explore the biological activities of the isolated metabolites and to relate these with the traditional uses of this plant.

\section{Acknowledgement}

MAR is grateful to the Ministry of Education, Government of the People's Republic of Bangladesh for a research grant (LS 2017326) to him for the period of July 2017- June 2020 to accomplish the work.

\section{References}

Chowdhury, A., Alam, M.A., Rashid, R.B., Al-Mansur, M.A., Rahman, M.S. and Rashid, M.A. 2013. Steroids and triterpenoids from Corypha taliera Roxb: a critically endangered palm species of Bangladesh. Res. J. Med. Plants, 7, 125-129. 
Cragg, G.M. and Newman, D.J. 2013. Natural products: a continuing source of novel drug leads. Biochim. Biophys. Acta. 1830, 3670-3695.

Fahad, T.A., Kuddus, M.R. and Hasan, C.M. 2020. Phytochemical and biological studies of bark extract of Miliusa velutina (Dunal) Hook. f. \& Thomson. Dhaka Univ. J. Pharm. Sci. 19, 125-131.

Ghosh, P., Chakraborty, P., Mandal, A., Rasul, M.G., Chakraborty, M. and Saha, A. 2011. Triterpenoids from Schleichera oleosa of Darjeeling foothills and their antimicrobial activity. Indian J. Pharm. Sci. 73, 231-233.

Gomes, R.A., Maciel, J.K.S., Agra, M.F., Souza, M.F.V., Falcão-Silva, V.S. and Siqueira-Junior, J.P. 2011. Phenolic compounds from Sidastrum micranthum (A. St.-Hil.) Fryxell and evaluation of acacetin and 7,4'-dio-methylisoscutellarein as modulator of bacterial drug resistance. Quim. Nova. 34, 1385-1388.

Goswami, S. and Singh, R.P. 2017. Ayurvedic, phytochemical and pharmacological review of Schleichera oleosa (Lour.) Oken: a traditional plant with enormous biological activity. World J. Pharm. Res. 6, 295-309.

Haque, A., Siddiqi, M. M., Rahman, A., Hasan, C. \& Chowdhury, A. 2013. Isolation of betulinic acid and 2,3-dihydroxyolean-12-en-28-oic acid from the leaves of Callistemon linearis. Dhaka Univ. J. Sci. 61, 211212.

Hwang, D., Hyun, J., Jo, G., Koh, D. and Lim, Y. 2011. Synthesis and complete assignment of NMR data of 20 chalcones. Magn. Reson. Chem. 49, 41-45.

Islam, M., Jannat, T., Kuddus, M.R., Rashid, M.A. and Haque, M.R. 2019. In vitro and in vivo evaluation of pharmacological potentials of Campsis radicans $\mathrm{L}$. Clinical Phytosci. 5, 42.

McChesney, J.D., Venkataraman, S.K. and Henri, J.T. 2007. Plant natural products: back to the future or into extinction. Phytochemistry 68, 2015-2022.

Mohapatra, S.P. and Sahoo, H.P. 2008. An ethno-medicobotanical study of Bolangir, Orissa, India: native plant remedies against gynecological diseases. Ethnobot Leaflets. 12, 846-854.
Moniruzzaman, M., Kuddus, M.R., Chowdhury, A.M.S. and Rashid, M.A. 2019. Antioxidant, antimicrobial, anti-diarrheal and analgesic activities of Diospyros malabarica (Desr.) Kostel. Bangladesh Pharm. J. 22, 27-33.

Palanuvej, C. and Vipunngeun, N. 2008. Fatty acid constituents of Schleichera oleosa (Lour) Oken seed oil. J. Health Res. 22, 203.

Pettit, G.R., Numata, A., Cragg, G.M., Herald, D.L., Takada, T., Iwamoto, C., Riesen, R., Schmidt, J.M., Doubek, D.L. and Goswami, A. 2000. Isolation and structures of schleicherastatins 1-7 and schleicheols 1 and 2 from the teak forest medicinal tree Schleichera oleosa. J. Nat. Prod. 63, 72-78.

Pokhrel, L., Sharma, B. and Bajracharya, G.B. 2015. Brine shrimp lethality and antibacterial activity of extracts from the bark of Schleichera oleosa. J. Coast. Life Med. 3, 645-647.

Rahman, S., Hasnat, A., Hasan, C.M., Rashid, M.A. and Ilias, M. 2001. Pharmacological evaluation of Bangladeshi medicinal plants-a review. Pharma. Biol. 39, 1-6.

Rashid, M.A., Haque, M.R., Sikder, M.A., Chowdhury, A.A., Rahman, M.S. and Hasan, C. 2015. Review on chemistry and bioactivities of secondary metabolites from some medicinal plants and microbes of Bangladesh. Bangladesh Pharm. J. 17, 1-17.

Sufian M.A., Begum, F., Haque, M.R., Hasan, C.M. and Rashid, M.A. 2015. Sterol and triterpenoids from Hygrophila schulli Buch-Ham. Bangladesh J. Bot. 44, 319-321.

Thind, T.S., Singh, R., Kaur, R., Rampal, G. and Arora, S. 2011. In vitro antiradical properties and total phenolic contents in methanol extract/fractions from bark of Schleichera oleosa (Lour.) Oken. Med. Chem. Res. 20, 254-260.

Uddin, S.J., Grice, I.D. and Tiralongo, E. 2011. Cytotoxic effects of Bangladeshi medicinal plant extracts. Evid. Based Complement. Alternat. Med. Volume 2011, Article ID 578092.

Veeresham C. 2012. Natural products derived from plants as a source of drugs. J. Adv. Pharm. Technol. Res. 3, 200-201. 